\title{
Conformance Testing of Balana: An Open Source Implementation of the XACML3.0 Standard
}

\author{
Sung-Ju Fan Chiang \\ Department of Computer Science \\ Boise State University \\ Boise, ID 83725, USA \\ sungjufanchiang@u.boisestate.edu
}

\author{
Daniel W. Chen \\ Department of Economics \\ University of Chicago \\ Chicago, IL 60637, USA \\ danielwchen@uchicago.edu
}

\author{
Dianxiang Xu \\ Department of Computer Science \\ Boise State University \\ Boise, ID 83725, USA \\ dianxiangxu@boisestate.edu
}

\begin{abstract}
As a new generation access control method, Attribute-Based Access Control (ABAC) has gained increasing attention. Currently, Balana is the only open-source implementations of XACML 3.0, which is an OASIS standard for specifying ABAC. Considering that XACML is much more complex than traditional access control models, conformance testing of any XACML implementation is an important problem. Using a non-conformance implementation may lead to misunderstanding of access decisions or even security violations. This paper presents an approach to conformance testing of Balana, focusing on the main elements of the XACML3.0 language, such as targets, rules, policies, and policy sets. In particular, we have thoroughly tested the key rule combining algorithms in policies and policy combining algorithms in policy sets. This has revealed several conformance issues.
\end{abstract}

Keywords-attribute-based access control; Balana; conformance testing; decision tables; XACML.

\section{INTRODUCTION}

Access control is a fundamental mechanism for preventing malicious or accidental security violation. An access control policy specifies the conditions under which access to resources can be granted and to whom [12]. With the increasing system complexity, access control methods have evolved from Mandatory Access Control (MAC), Discretionary Access Control (DAC), Role-Based Access Control (RBAC) to Attribute-Based Access Control (ABAC). ABAC combines various attributes of authorization elements into access control decisions [6]. These attributes are predefined characteristics of subjects (e.g., job title and age), resources (e.g., data, programs, and networks), actions, and environments (e.g., current time and IP address.

XACML (eXtensible Access Control Markup Language) [11] is an OASIS standard for specifying ABAC policies in the $\mathrm{XML}$ format. It can be used within a large enterprise or across multiple organizations. Currently Balana [1] is the only open source implementations of XACML 3.0. It is worth pointing out that the original open source implementation of XACML from Sun Microsystems, Inc. only supports 1.0 and 2.0. While it is believed to be upgraded to 3.0 in Oracle's Identity Server, the upgraded version is no longer open source. XACML3.0 is much more complex than traditional access control methods such as RBAC. For example, XACML 3.0 provides various combining algorithms to support rule and policy composition. A combining algorithm aims at rendering a single access decision by combining the decisions of individual access control rules or policies. The standard specification of XACML3.0 lacks a rigorous representation of the semantics of the combining algorithms. Our prior work on the formalization of the semantic differences between various combining algorithms in XACML 3.0 shows that, for any pair of rule (or policy) combining algorithms studied, they can be functionally equivalent with respect to certain rules (or policies) [13]. The similarities and differences among the combining algorithms are subtle. This increases the likelihood of having errors. Thus, conformance testing of any XACML3.0 implementation is an important issue. Using a non-conformance XACML implementation may lead to misunderstanding of access decisions or even security violations.

In this paper, we present our work on the systematic testing of conformance between Balana and XACML3.0. It focuses on the main language elements of XACML3.0, such as targets, rules, policies (including rule combining algorithms), and policy sets (including policy combining algorithms). As $\mathrm{XACML}$ is a logic-based language, we use decision tables as the main technique for formulating the semantics of these language elements and their test requirements. Although decision tables are a traditional technique, the particular decision tables resulted from this research provide an accurate understanding of the meanings of the main XACML 3.0 elements. They offer important guidelines for XACML3.0 practitioners. In addition, they are useful for testing other implementations of XACML3.0 in order to verify functional conformance. Based on the decision tables, the conformance tests for targets, rules, and policies are created manually. For policy sets and policy combining algorithms, however, all conformance tests are generated automatically from the existing conformance tests. In our experiment, all conformance tests are executed automatically. The results have revealed several conformance issues in Balana.

The remainder of this paper is organized as follows. Section II gives a brief introduction to the main XACML language elements. Section III describes our conformance testing method. Section IV presents the results of our conformance testing experiment. Section V reviews related work. Section VI concludes this paper.

\section{XACML LANGUAGE ElEMENTS}

The first-class entities in XACML are policy and policy set. A policy is composed of an optional policy target, one or more rules, and a rule combining algorithm. A policy set consists of 
an optional policy set target, one or more sub-policy sets or policies, and a policy combining algorithm. Figure 1 shows the main elements of XACML 3.0 and their relationships.

A rule consists of a target, a condition, and an effect. The target is a logical expression that specifies the set of requests to which the rule is intended to apply. The logical operators are AnyOf and AllOf. Specifically, a target consists of zero or more Any Of clauses, and each AllOf clause is made up of one or more match predicate. The condition is a Boolean expression that refines the applicability of the rule established by the target. Predicates in target and condition are defined over attributes and attribute values (e.g., gender is male).

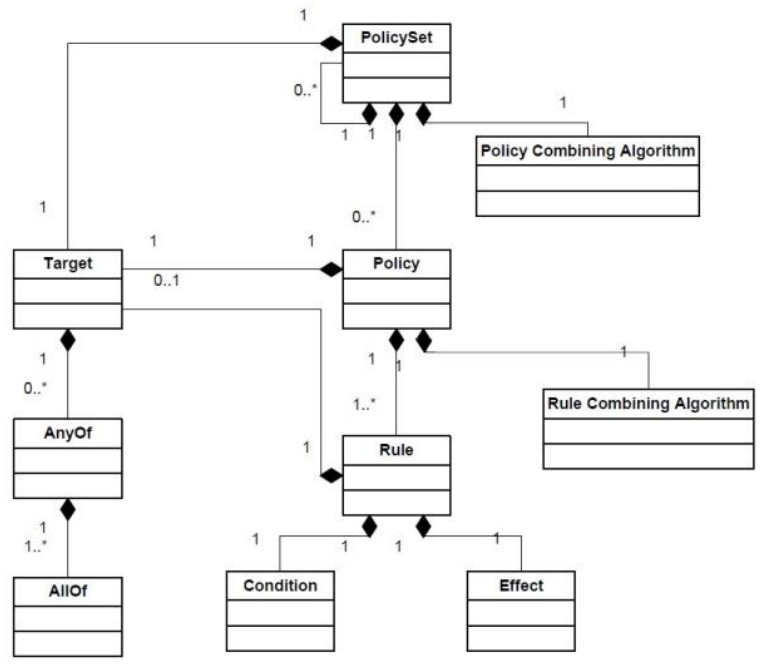

Figure 1. Main language elements of XACML 3.0 [11]

An access request consists of attribute and value pairs. Given a request, the decision of a policy depends on the policy target, the decisions of individual rules in the policy, and the rule combining algorithm. Each rule may yield one of the following decisions if the policy target evaluates to true:

- Permit: access is granted when the rule effect is Permit and the rule target evaluates to Match and the rule condition evaluates to true.

- Deny: access is denied when the rule effect is Deny, the rule target evaluates to Match, and the rule condition evaluates to true.

- Not-Applicable, denoted as N/A in this paper: either the rule target evaluates to No Match or the rule condition evaluates to false.

- Indeterminate Deny, denoted as $I(D)$ : An error occurred when the rule target or the rule condition was evaluated. The decision could have evaluated to Deny if no error had occurred.

- Indeterminate Permit, denoted as $I(P)$ : An error occurred when the rule target or the rule condition was evaluated. The decision could have evaluated to Permit if no error had occurred.

The rule combining algorithm combines the decisions of individual rules into a single policy-level decision. In addition to the above decisions, a policy decision can be Indeterminate Deny Permit, denoted as $I(D P)$. $I(D), I(P)$ and $I(D P)$ will be a plain Indeterminate if it is the final decision returned by the XACML engine.

XACML3.0 provides 11 rule combining algorithms. Four of them are for compatibility support of old versions - Legacy Ordered-deny-overrides, Legacy Permit-overrides, Legacy Ordered-permit-overrides, and Legacy Ordered-permitoverrides. In Balana, the implementations of Ordered-denyoverrides and Ordered-permit-overrides are the same as Denyoverrides and Permit-overrides. Thus this paper focuses on the following five rule combining algorithms:

- Deny-overrides: Intended for those cases where a Deny decision should have priority over a Permit decision;

- Permit-overrides: Intended for the cases where a Permit decision should have priority over a Deny decision.

- Deny-unless-permit: Intended for those cases where a Permit decision should have priority over a Deny decision, and an Indeterminate or N/A must never be the result.

- Permit-unless-deny: Intended for those cases where a Deny decision should have priority over a Permit decision, and an Indeterminate or N/A must never be the result.

- First-applicable: Rules are evaluated in the order in which they are listed. If a rule's target matches and condition evaluates to True, then return the rule's effect (Permit or Deny). If the target or condition evaluates to False, the next rule is evaluated. If no further rule exists, then return N/A. If an error occurs, then return Indeterminate, with the appropriate error status.

Given a request, a policy set yields one of the six decisions: Permit, Deny, N/A, $I(D), I(P)$, and $I(D P)$. It depends on the policy set target, the decisions of individual policy sets and policies in the policy set, and the policy combining algorithm. XACML 3.0 specifies 12 policy-combing algorithms. Similar to the reasons for the selected rule combining algorithms, this paper focuses on the six policy combining algorithms: Denyoverrides, Deny-unless-permit, Permit-overrides, Permitunless-deny, First-applicable, and Only-one-applicable.

\section{The CONFORMAnCE Testing Method}

Although XACML has a number of language elements, policy and policy set are the first-class executable units. Thus, an executable conformance test case must include a policy (or policy set), an access request, and expected response. The policy (or policy set) and access request are called test input, whereas the expected response is called test oracle. Test oracles of all conformance tests are defined per the XACML3.0 standard specification. When creating conformance tests for other language elements such as policy targets, rule targets, rule conditions, and rules, we also need to create policy files. When a conformance test is executed with Balana, we verify whether the actual response produced by Balana is the same as the test oracle. If not, Balana does not conform to the standard specification and the test is called a non-conformance test. 
The main technique used for the conformance testing is decision tables because XACML is essentially a logic-based language. Unlike the traditional mathematical logic that has two truth values (true and false), XACML is more like multivalued logic due to the consideration of error conditions. For example, a match predicate could evaluate to True, False, or Indeterminate (which means an error has occurred during the evaluation).

We build decision tables for the main XACML language elements based on their semantics described in the standard specification. The decision tables capture the requirements of conformance testing. Concrete conformance tests are then created or generated to cover every entry. Specifically, the tests for targets, rules, and policies are created manually, whereas the tests for policy sets (i.e., sample policy sets and access requests) are generated from the existing tests for policies (i.e., sample policies and access requests).

In the following, we present the test requirements of the main XACML language elements in the form of decision tables. The decision tables are not only useful for the conformance testing, but can help XACML users get an accurate understanding of XACML policies. We start with the basic elements (i.e., targets and rules) and then focus on policies and policy sets.

\section{A. Conformance Testing of Targets}

The target in a rule, policy, or policy set consists of zero or more AnyOf clauses. An AnyOf clause consists of a sequence of AllOf clauses. An AllOf clause consists of a sequence of match predicates, which are the basic element of targets. A match predicate matches an attribute name with an attribute value. A match predicate evaluates to True, False, or Indeterminate (i.e., an error has occurred during evaluation). A target can evaluate to Match, No Match, or Indeterminate. Table 1 shows the decision table of target evaluation per the XACML3.0 standard specification. AllOf is similar to the logical operator "and" - an AllOf clause evaluates to Match if and only if all match predicates in the AllOf clause evaluate to true. It evaluates to indeterminate if one of the match predicate evaluates to Indeterminate. Any Of is similar to the logical operator "or". An Any Of clause evaluates to true if one of the AllOf clauses evaluate to true.

Table 1 essentially specifies the minimum test requirements for the target element in XACML 3.0. Our test design ensures that each entry in the decision table is covered by at least one conformance test.

TABLE 1. DECISION TABLE FOR TARGET EVALUATION

\begin{tabular}{|c|c|c|c|c|c|c|c|c|}
\hline \multicolumn{4}{|c|}{ AnyOf1 } & \multicolumn{4}{|c|}{ AnyOf2 } & \multirow{3}{*}{$\begin{array}{l}\text { Deci } \\
\text { sion }\end{array}$} \\
\hline \multicolumn{2}{|c|}{ AllOf1 } & \multicolumn{2}{|c|}{ AllOf2 } & \multicolumn{2}{|c|}{ AllOf3 } & \multicolumn{2}{|c|}{ AllOf4 } & \\
\hline $\begin{array}{l}\text { Mat } \\
\text { ch1 }\end{array}$ & $\begin{array}{l}\text { Mat } \\
\text { ch2 }\end{array}$ & $\begin{array}{l}\text { Mat } \\
\text { ch3 }\end{array}$ & $\begin{array}{l}\text { Mat } \\
\text { ch4 }\end{array}$ & $\begin{array}{l}\text { Mat } \\
\text { ch5 }\end{array}$ & $\begin{array}{l}\text { Mat } \\
\text { ch6 }\end{array}$ & $\begin{array}{l}\text { Mat } \\
\text { ch7 }\end{array}$ & $\begin{array}{l}\text { Mat } \\
\text { ch8 }\end{array}$ & \\
\hline $\mathrm{T}$ & $\mathrm{T}$ & $\mathrm{T}$ & $\mathrm{T}$ & $\mathrm{T}$ & $\mathrm{T}$ & $\mathrm{T}$ & $\mathrm{T}$ & M \\
\hline $\mathrm{T}$ & $\mathrm{T}$ & $\mathrm{T}$ & $\mathrm{T}$ & $\mathrm{T}$ & $\mathrm{T}$ & $\mathrm{T}$ & I & $\mathrm{M}$ \\
\hline $\mathrm{T}$ & $\mathrm{T}$ & $\mathrm{T}$ & $\mathrm{T}$ & $\mathrm{T}$ & $\mathrm{T}$ & $\mathrm{T}$ & $\mathrm{F}$ & M \\
\hline $\mathrm{T}$ & $\mathrm{T}$ & $\mathrm{T}$ & $\mathrm{T}$ & $\mathrm{T}$ & $\mathrm{I}$ & $\mathrm{T}$ & $\mathrm{I}$ & $\mathrm{I}$ \\
\hline $\mathrm{T}$ & $\mathrm{T}$ & $\mathrm{T}$ & $\mathrm{T}$ & $\mathrm{T}$ & I & $\mathrm{T}$ & $F$ & I \\
\hline $\mathrm{T}$ & $\mathrm{T}$ & $\mathrm{T}$ & $\mathrm{T}$ & $\mathrm{T}$ & $\mathrm{F}$ & $\mathrm{T}$ & $\mathrm{F}$ & $\mathrm{N}$ \\
\hline $\mathrm{T}$ & $\mathrm{T}$ & $\mathrm{T}$ & I & $\mathrm{T}$ & $\mathrm{T}$ & $\mathrm{T}$ & I & $\mathrm{M}$ \\
\hline
\end{tabular}

\begin{tabular}{|c|c|c|c|c|c|c|c|c|}
\hline $\mathrm{T}$ & $\mathrm{T}$ & $\mathrm{T}$ & $\mathrm{I}$ & $\mathrm{T}$ & $\mathrm{T}$ & $\mathrm{T}$ & $\mathrm{F}$ & $\mathrm{M}$ \\
\hline $\mathrm{T}$ & $\mathrm{T}$ & $\mathrm{T}$ & $\mathrm{I}$ & $\mathrm{T}$ & $\mathrm{I}$ & $\mathrm{T}$ & $\mathrm{I}$ & $\mathrm{I}$ \\
\hline $\mathrm{T}$ & $\mathrm{T}$ & $\mathrm{T}$ & $\mathrm{I}$ & $\mathrm{T}$ & $\mathrm{I}$ & $\mathrm{T}$ & $\mathrm{F}$ & $\mathrm{I}$ \\
\hline $\mathrm{T}$ & $\mathrm{T}$ & $\mathrm{T}$ & $\mathrm{I}$ & $\mathrm{T}$ & $\mathrm{F}$ & $\mathrm{T}$ & $\mathrm{F}$ & $\mathrm{N}$ \\
\hline $\mathrm{T}$ & $\mathrm{T}$ & $\mathrm{T}$ & $\mathrm{F}$ & $\mathrm{T}$ & $\mathrm{T}$ & $\mathrm{T}$ & $\mathrm{F}$ & $\mathrm{M}$ \\
\hline $\mathrm{T}$ & $\mathrm{T}$ & $\mathrm{T}$ & $\mathrm{F}$ & $\mathrm{T}$ & $\mathrm{I}$ & $\mathrm{T}$ & $\mathrm{I}$ & $\mathrm{I}$ \\
\hline $\mathrm{T}$ & $\mathrm{T}$ & $\mathrm{T}$ & $\mathrm{F}$ & $\mathrm{T}$ & $\mathrm{I}$ & $\mathrm{T}$ & $\mathrm{F}$ & $\mathrm{I}$ \\
\hline $\mathrm{T}$ & $\mathrm{T}$ & $\mathrm{T}$ & $\mathrm{F}$ & $\mathrm{T}$ & $\mathrm{F}$ & $\mathrm{T}$ & $\mathrm{F}$ & $\mathrm{N}$ \\
\hline $\mathrm{T}$ & $\mathrm{I}$ & $\mathrm{T}$ & $\mathrm{I}$ & $\mathrm{T}$ & $\mathrm{I}$ & $\mathrm{T}$ & $\mathrm{I}$ & $\mathrm{I}$ \\
\hline $\mathrm{T}$ & $\mathrm{I}$ & $\mathrm{T}$ & $\mathrm{I}$ & $\mathrm{T}$ & $\mathrm{I}$ & $\mathrm{T}$ & $\mathrm{F}$ & $\mathrm{I}$ \\
\hline $\mathrm{T}$ & $\mathrm{I}$ & $\mathrm{T}$ & $\mathrm{I}$ & $\mathrm{T}$ & $\mathrm{F}$ & $\mathrm{T}$ & $\mathrm{F}$ & $\mathrm{N}$ \\
\hline $\mathrm{T}$ & $\mathrm{I}$ & $\mathrm{T}$ & $\mathrm{F}$ & $\mathrm{T}$ & $\mathrm{I}$ & $\mathrm{T}$ & $\mathrm{F}$ & $\mathrm{I}$ \\
\hline $\mathrm{T}$ & $\mathrm{I}$ & $\mathrm{T}$ & $\mathrm{F}$ & $\mathrm{T}$ & $\mathrm{F}$ & $\mathrm{T}$ & $\mathrm{F}$ & $\mathrm{N}$ \\
\hline $\mathrm{T}$ & $\mathrm{F}$ & $\mathrm{T}$ & $\mathrm{F}$ & $\mathrm{T}$ & $\mathrm{F}$ & $\mathrm{T}$ & $\mathrm{F}$ & $\mathrm{N}$ \\
\hline
\end{tabular}

$\mathrm{T}$ stand for "True", I stand for "Indeterminate", F stand for "False", M stand for "Match", N stand for "No match".

\section{B. Conformance Testing of Rules}

A rule consists of rule target, rule condition, and rule effect (either Permit or Deny). Rule target (or rule condition) is optional and evaluates to Match (or True) when it is absent. Rule condition evaluates to True, False, or Indeterminate. Table 2 shows the decision table of rules, where $D / C$ refers to "don't care". In the case of rule condition, $D / C$ means that the evaluation result of the rule condition is either True, False, or Indeterminate. In the case of rule effect, $D / C$ means either Permit or Deny. For example, when the rule target evaluates to Indeterminate and the rule effect is permit, the rule's decision is $I(P)$, regardless of the evaluation result of the rule condition. When the rule target evaluates to No Match, the rule's decision is N/A regardless of the rule condition and rule effect. Our test design ensures that each entry is covered by at least one test.

TABLE 2. DECISION TABLE FOR RULE EVALUATION

\begin{tabular}{|c|c|c|c|}
\hline $\begin{array}{c}\text { Evaluation } \\
\text { of Rule } \\
\text { Target }\end{array}$ & $\begin{array}{c}\text { Evaluation of } \\
\text { Rule } \\
\text { Condition }\end{array}$ & $\begin{array}{c}\text { Rule } \\
\text { Effect }\end{array}$ & $\begin{array}{c}\text { Rule } \\
\text { Decision }\end{array}$ \\
\hline Match & True & Permit & Permit \\
\hline Match & True & Deny & Deny \\
\hline Match & False & D/C & N/A \\
\hline Match & Indeterminate & Permit & I(P) \\
\hline Match & Indeterminate & Deny & I(D) \\
\hline No Match & D/C & D/C & N/A \\
\hline Indeterminate & D/C & Permit & I(P) \\
\hline Indeterminate & D/C & Deny & I(D) \\
\hline
\end{tabular}

\section{Conformance Testing of Policies}

The main elements of a policy include a policy target, one or more rules, and a rule combining algorithm. Table 3 shows a general decision table about how a policy is evaluated per the XACML3.0 specification. Given a request, if it matches the policy target, then the policy decision depends on the decisions of individual rules and the rule combining algorithm. If the request does not match the policy target, the policy decision is N/A regardless of the decisions of individual rules. If the policy target evaluates to Indeterminate (i.e., an error has occurred), the policy decision depends on the rule decisions.

The decision tables for rule combining algorithms are created according to the descriptions and pseudo code in the XACML3.0 specification. They are applied when a given 
request matches the policy target. Table 4 shows the decision table for the Deny-overrides rule combining algorithm. The decision of an individual rule can be Permit, Deny, N/A, I(D), or $I(P)$. Table 4 shows all of the 25 combinations of two rules. In particular, if one rule evaluates to Deny, the combined decision is Deny - this reflects the meaning of Deny-overrides. When there are more than two rules, the combined decision of $n-1$ rules can be combined with the $n$-th rule to obtain the policy-level decision.

TABLE 3. DECISION TABLE FOR POLICY EVALUATION

\begin{tabular}{|c|c|c|}
\hline $\begin{array}{c}\text { Evaluation Result } \\
\text { of Policy Target }\end{array}$ & $\begin{array}{c}\text { Rule } \\
\text { Decisions }\end{array}$ & Policy Decision \\
\hline Match & Deny & \multicolumn{1}{|c|}{} \\
\hline Match & Permit & \multirow{2}{*}{$\begin{array}{c}\text { Specified by the } \\
\text { rule-combining } \\
\text { algorithm }\end{array}$} \\
\hline Match & N/A & \\
\hline Match & I(D) & \\
\hline Match & I(P) & \\
\hline No Match & D/C & N/A \\
\hline Indeterminate & Deny & I(D) \\
\hline Indeterminate & Permit & I(P) \\
\hline Indeterminate & N/A & N/A \\
\hline Indeterminate & I(D) & I(D) \\
\hline Indeterminate & I(P) & I(P) \\
\hline
\end{tabular}

TABLE 4. DECISION TABLE FOR THE DENY-OVERRIDES RULECOMBINING ALGORITHM

\begin{tabular}{|c|c|c|c|c|c|c|}
\hline \multirow{2}{*}{ Deny-overrides } & \multicolumn{5}{|c|}{ Decision of the first rule } \\
\cline { 2 - 7 } & Permit & Deny & N/A & I(D) & I(P) \\
\hline \multirow{2}{*}{$\begin{array}{c}\text { Decision } \\
\text { of the } \\
\text { second } \\
\text { rule }\end{array}$} & Permit & Permit & Deny & Permit & $\mathrm{I}(\mathrm{D})$ & Permit \\
\cline { 2 - 7 } & Deny & Deny & Deny & Deny & Deny & Deny \\
\cline { 2 - 7 } & I(D) & I (D) & Deny & I(D) & I(D) & I(DP) \\
\cline { 2 - 7 } & I(P) & Permit & Deny & I(P) & $\mathrm{I}(\mathrm{DP})$ & $\mathrm{I}(\mathrm{P})$ \\
\hline
\end{tabular}

When the name of a rule combining algorithm is also used as a policy combining algorithm, the decision table for the policy combining algorithm (e.g., Table 6) is more general than the decision table of the corresponding rule combining algorithms (e.g., Table 5). Thus, this paper does not present the decision tables of other rule combining algorithms.

Based on the decision tables for the policy evaluation and the rule combining algorithms, we create policy files and request files to cover all entries of each decision table. A policy file and a request file form the input of a conformance test. The test oracle is the corresponding policy decision in the decision table. For an entry of $D / C$, we create a conformance test to cover each possible value of that entry.

To execute the tests automatically, we specify all the conformance tests (policy file, request file, and oracle value) in a spreadsheet. For each entry of the spreadsheet, our test execution framework will invoke Balana with the corresponding policy file and request file, compare the actual response from Balana with the oracle value, and report the verdict (pass/fail).

\section{Automated Conformance Testing of Policy Sets}

The main elements for a policy set include a policy set target, sub-policies or policy sets, and a policy combining algorithm. The evaluation of a policy set is similar to that of policy evaluation. Table 5 shows the general decision table for policy set evaluation. Given a request, if it matches the policy set target, then the policy set decision depends on the decisions of individual sub-policies/policy sets, and the policy combining algorithm. If the request does not match the policy set target, the policy set decision is N/A regardless of the decisions of individual sub-policies/policy sets. If the policy set target evaluates to Indeterminate (i.e., an error has occurred), the policy set decision depends on the decisions of individual subpolicies/policy sets.

TABLE 5. DECISION TABLE FOR POLICY SET EVALUATION

\begin{tabular}{|c|c|c|}
$\begin{array}{c}\text { Policy Set } \\
\text { Target }\end{array}$ & $\begin{array}{c}\text { Decisions of Sub- } \\
\text { Policies or Policy } \\
\text { Sets }\end{array}$ & $\begin{array}{c}\text { Policy Set } \\
\text { Decision }\end{array}$ \\
\hline Match & Deny & $\begin{array}{c}\text { Specified by } \\
\text { the policy- } \\
\text { combining } \\
\text { algorithm }\end{array}$ \\
\hline Match & Permit & N/A \\
\hline Match & N/A & I(D) \\
\hline Match & I(D) & I(P) \\
\hline No Match & I(P) & N/A \\
\hline Indeterminate & D/C & I(D) \\
\hline Indeterminate & Permit & I(P) \\
\hline Indeterminate & N/A & I(DP) \\
\hline Indeterminate & I(D) & \\
\hline Indeterminate & I(P) &
\end{tabular}

Tables 6-11 are the decision tables for the six policy combining algorithms. An important feature of this work is that we automatically generate conformance tests for policy sets from the decision tables of the policy combining algorithms and the existing conformance tests for policies.

Let us use the Deny-overrides policy combining algorithm as an example. Table 6 is its decision table. We need to create a conformance test for each entry in Table 6 (i.e., a total of 36 tests for Table 6). Consider the entry where the decision of the first policy in the policy set is Permit and the decision of the second policy in the policy set is Deny. Our goal is to create a policy set file and a request file such that (a) the policy set has two policies, (b) the policy combining algorithm is Denyoverrides, (c) the first policy evaluates to Permit with respect to the request, and (d) the second policy evaluates to Deny with respect to the request. We generate such a policy set file and a request file as follows:

(1) Find an existing policy test including a policy file and a request file such that the policy decision should be Permit. Let us denote the policy file as $P l$ and the request file as $R l$.

(2) Find an existing policy test including a policy file and a request file such that the policy decision should be Deny. Let us denote the policy as $P 2$ and the request as $R 2$.

(3) Find the attribute names in both policy tests. For any attribute that appears in both policy tests, rename the attribute in the second policy test ( $P 2$ and $R 2)$. Let $P 2$ ' and $R 2$ ' be the revised policy and request. 
(4) Generate a policy set file from $P 1$ and $P 2$ ' using the Deny-overrides as the policy combining algorithm. The policy set target is set to empty (which always evaluates to Match) or move the target of $P 1$ or $P 2$ ' to the policy set target.

(5) Generate a request file by composing the attributes and their values in $R 1$ and $R 2$ '.

(6) The oracle value of the policy set conformance test is Deny, according to the decision table.

Note that the renaming in step (3) is critical. It resolves the naming conflicts - the same attribute from different tests may have different meanings. Without this step, (4) and (5) would not guarantee that the first policy in the policy set evaluates to Permit or the second policy in the policy set to Deny.

For each policy combining algorithm, the generated conformance tests (including policy set file, request file, and oracle value) are specified in a spreadsheet. For each entry of the spreadsheet, the test execution framework will call Balana with the corresponding policy set file and request file, compare the actual response from Balana with the oracle value, and report the verdict (pass/fail).

TABLE 6. DECISION TABLE FOR THE DENY-OVERRIDE POLICYCOMBINING ALGORITHM

\begin{tabular}{|c|c|c|c|c|c|c|c|}
\hline \multirow{2}{*}{\multicolumn{2}{|c|}{ Deny-overrides }} & \multicolumn{6}{|c|}{ Decision of the first policy or policy set } \\
\hline & & Permit & Deny & N/A & I (D) & $\mathbf{I}(\mathbf{P})$ & I (DP) \\
\hline \multirow{6}{*}{$\begin{array}{c}\text { Decision } \\
\text { of the } \\
\text { second } \\
\text { policy or } \\
\text { policy set }\end{array}$} & & Permit & Deny & Permit & $\mathrm{I}(\mathrm{DP})$ & Permit & $\mathrm{I}(\mathrm{DP})$ \\
\hline & & eny & De & Deny & Deny & Deny & \\
\hline & & Per & $\mathrm{De}$ & N/A & $\mathrm{I}(\mathrm{D})$ & $\mathrm{I}(\mathrm{P})$ & \\
\hline & I(D) & I (DP) & De & $\mathrm{I}(\mathrm{D})$ & $\mathrm{I}(\mathrm{D})$ & $\mathrm{I}(\mathrm{DP})$ & I (DP) \\
\hline & $\mathbf{I}(\mathbf{P})$ & Permit & De & $\mathrm{I}(\mathrm{P})$ & $\mathrm{I}(\mathrm{DP})$ & $\mathrm{I}(\mathrm{P})$ & I (DP) \\
\hline & I(DP) & I (DP) & Deny & I (DP) & I (DP) & $\mathrm{I}(\mathrm{DP})$ & I (DP) \\
\hline
\end{tabular}

TABLE 7. DECISION TABLE FOR THE PERMIT-OVERRIDE POLICY - COMBINING ALGORITHMS

\begin{tabular}{|c|c|c|c|c|c|c|c|}
\hline \multirow{2}{*}{\multicolumn{2}{|c|}{ Permit-overrides }} & \multicolumn{6}{|c|}{ Decision of the first policy or policy set } \\
\hline & & Permit & Deny & N/A & I (D) & $\mathbf{I}(\mathbf{P})$ & I (DP) \\
\hline \multirow{6}{*}{$\begin{array}{c}\text { Decision of } \\
\text { the second } \\
\text { policy or } \\
\text { policy set }\end{array}$} & Permit & Permit & Permit & Permit & Permit & Permit & Permit \\
\hline & De & Permit & Deny & Deny & Deny & $\mathrm{I}(\mathrm{P})$ & I (DP) \\
\hline & N/A & Permit & Deny & N/A & I (D) & $\mathrm{I}(\mathrm{P})$ & I (DP) \\
\hline & I(D) & Permit & Deny & I (D) & I (D) & $\mathrm{I}(\mathrm{DP})$ & $\mathrm{I}(\mathrm{DP})$ \\
\hline & $\mathbf{I}(\mathbf{P})$ & Permit & $\mathrm{I}(\mathrm{P})$ & $\mathrm{I}(\mathrm{P})$ & I (DP) & $\mathrm{I}(\mathrm{P})$ & I (DP) \\
\hline & I(DP) & Permit & I (DP) & I (DP) & I (DP) & I (DP) & $\mathrm{I}(\mathrm{DP})$ \\
\hline
\end{tabular}

TABLE 8. DECISION TABLE FOR THE DENY-UNLESS-PERMIT POLICY-COMBINING ALGORITHMS

\begin{tabular}{|c|c|c|c|c|c|c|c|}
\hline \multirow{2}{*}{\multicolumn{2}{|c|}{$\begin{array}{l}\text { Deny-unless- } \\
\text { permit }\end{array}$}} & \multicolumn{6}{|c|}{ Decision of the first policy or policy set } \\
\hline & & Permit & Deny & N/A & I (D) & I (P) & I (DP) \\
\hline \multirow{6}{*}{$\begin{array}{l}\text { Decision of } \\
\text { the second } \\
\text { policy or } \\
\text { policy set }\end{array}$} & Permit & Permit & Permit & Permit & Permit & Permit & \\
\hline & Deny & Permit & Deny & Deny & Deny & \begin{tabular}{|l|} 
Deny \\
\end{tabular} & \\
\hline & N/A & Perm & Deny & Der & De & De & \\
\hline & I(D) & Permit & Deny & Deny & Deny & Del & \\
\hline & $\mathbf{I}(\mathbf{P}$ & Perm & Deny & Der & Deny & Der & \\
\hline & I(DP) & Permit & Deny & Deny & Deny & Deny & Deny \\
\hline
\end{tabular}

TABLE 9. DECISION TABLE FOR THE PERMIT-UNLESS-DENY POLICY-COMBINING ALGORITHMS

\begin{tabular}{|c|c|c|c|c|c|c|}
\hline $\begin{array}{c}\text { Permit-unless- } \\
\text { deny }\end{array}$ & \multicolumn{5}{|c|}{ Decision of the first policy or policy set } \\
\cline { 2 - 6 } & Permit & Deny & N/A & $\mathbf{I}(\mathbf{D})$ & $\mathbf{I}(\mathbf{P})$ & $\mathbf{I}(\mathbf{D P})$ \\
\hline
\end{tabular}

\begin{tabular}{|l|c|c|c|c|c|c|c|}
\hline \multirow{4}{*}{$\begin{array}{c}\text { Decision } \\
\text { of the }\end{array}$} & Permit & Permit & Deny & Permit & Permit & Permit & Permit \\
\cline { 2 - 7 } second & Deny & Deny & Deny & Deny & Deny & Deny & Deny \\
\cline { 2 - 7 } policy or & N/A & Permit & Deny & Permit & Permit & Permit & Permit \\
\cline { 2 - 7 } policy set & I(D) & Permit & Deny & Permit & Permit & Permit & Permit \\
\cline { 2 - 6 } & I(D) & Permit & Deny & Permit & Permit & Permit & Permit \\
\hline \multirow{2}{*}{} & & Deny & Permit & Permit & Permit & Permit \\
\hline
\end{tabular}

TABLE 10. DECISION TABLE FOR THE FIRST-APPLICABLE POLICY- COMBINING ALGORITHMS

\begin{tabular}{|c|c|c|c|c|c|c|c|}
\hline \multirow{2}{*}{\multicolumn{2}{|c|}{ First-applicable }} & \multicolumn{6}{|c|}{ Decision of the first policy or policy set } \\
\hline & & Permit & Deny & N/A & I (D) & $\mathbf{I}(\mathbf{P})$ & I (DP) \\
\hline \multirow{6}{*}{$\begin{array}{l}\text { Decision } \\
\text { of the } \\
\text { second } \\
\text { policy or } \\
\text { policy set }\end{array}$} & Permit & Permit & Deny & Permit & $\mathrm{I}(\mathrm{D})$ & $\mathrm{I}(\mathrm{P})$ & I (DP) \\
\hline & Deny & Permit & Deny & Deny & I (D) & $\mathrm{I}(\mathrm{P})$ & I (DP) \\
\hline & $\mathbf{N} / \mathbf{A}$ & Permit & Deny & NA & I (D) & $\mathrm{I}(\mathrm{P})$ & I (DP) \\
\hline & I(D) & Permit & Deny & I (D) & I (D) & $\mathrm{I}(\mathrm{P})$ & I (DP) \\
\hline & $\mathbf{I}(\mathbf{P})$ & Permit & Deny & $\mathrm{I}(\mathrm{P})$ & I (D) & $\mathrm{I}(\mathrm{P})$ & $\mathrm{I}(\mathrm{DP})$ \\
\hline & I(DP) & Permit & Deny & $\mathrm{I}(\mathrm{DP})$ & I (D) & $\mathrm{I}(\mathrm{P})$ & I (DP) \\
\hline
\end{tabular}

TABLE 11. DECISION TABLE FOR THE ONLY-ONE-APPLICABLE POLICY-COMBINING ALGORITHM

\begin{tabular}{|c|c|c|c|c|c|}
\hline \multirow{2}{*}{\multicolumn{2}{|c|}{$\begin{array}{l}\text { Only-one- } \\
\text { applicable }\end{array}$}} & \multicolumn{4}{|c|}{ Decision of the first policy or policy set } \\
\hline & & Permit & Deny & N/A & I (Indeterminate) \\
\hline \multirow{4}{*}{$\begin{array}{c}\text { Decision of } \\
\text { the second } \\
\text { policy or } \\
\text { policy set }\end{array}$} & Permit & I & I & Permit & $\mathrm{I}$ \\
\hline & Deny & $\mathrm{I}$ & $\mathrm{I}$ & Deny & $\mathrm{I}$ \\
\hline & N/A & Permit & Deny & N/A & $\mathrm{I}$ \\
\hline & I & I & I & I & I \\
\hline
\end{tabular}

\section{Results of CONFORMANCE Testing}

Our conformance testing has revealed several nonconformance cases as summarized below. It is worth pointing out that these cases do not necessarily lead to security violations in an XACML application. It depends on how the responses are handled by the application's policy enforcement point. However, understanding the differences between Balana and the XACML standard specification is important for the users of Balana to correctly enforce access control policies.

The current implementation of the Permit-overrides rule and policy combining algorithm does not conform to the XACML3.0 specification with respect to the error conditions. Table 12 shows the three non-conformance tests for which Balana's responses are different from the test oracles per the XACML standard specification (refer to the decision table for Permit-overrides in Table 7). When the decisions of two policies in a policy set are N/A and Indeterminate Deny, or both Indeterminate Deny, the decision of the policy set should be Indeterminate Deny. However, the actual response of Balana is N/A.

TABLE 12. NON-CONFORMANCE TESTS OF THE PERMITOVERRIDES POLICY-COMBINING ALGORITHM

\begin{tabular}{|c|c|c|c|c|}
\hline \multirow{2}{*}{$\begin{array}{c}\text { Non- } \\
\text { Conformance } \\
\text { Test }\end{array}$} & \multicolumn{2}{|c|}{ Test Input } & \multirow{2}{*}{$\begin{array}{c}\text { Test } \\
\text { Oracle } \\
\text { per } \\
\text { XACML }\end{array}$} & \multirow[b]{2}{*}{$\begin{array}{c}\text { Actual } \\
\text { Result by } \\
\text { Balana }\end{array}$} \\
\hline & $\begin{array}{c}\text { Decision } \\
\text { of Policy } \\
1\end{array}$ & $\begin{array}{c}\text { Decision } \\
\text { of Policy } \\
2\end{array}$ & & \\
\hline 1 & N/A & $\mathrm{I}(\mathrm{D})$ & $\mathrm{I}(\mathrm{D})$ & N/A \\
\hline 2 & I(D) & N/A & I(D) & N/A \\
\hline 3 & I(D) & I(D) & I(D) & N/A \\
\hline
\end{tabular}

The current implementation of the Deny-overrides combining algorithm also has four non-conformance tests as 
shown in Table 13. For example, when the decisions of two policies in a policy set are $I(D)$ and Permit, the decision of the policy set should be $I(D P)$. However, the actual response of Balana is $I(D)$. When the decision of this policy set is the final response to the user, there will be no difference because both $I(D P)$ and $I(D)$ will result in a plain Indeterminate. However, when such a policy set is used by other policy sets, the nonconformance results may lead to different final decisions for access requests.

TABLE 13. NON-CONFORMANCE TESTS OF THE DENY-OVERRIDES POLICY-COMBINING ALGORITHM

\begin{tabular}{|c|c|c|c|c|}
\hline \multirow{2}{*}{$\begin{array}{c}\text { Non- } \\
\text { Conforma } \\
\text { nce Test }\end{array}$} & \multicolumn{2}{|c|}{ Test Input } & \multirow{2}{*}{$\begin{array}{c}\text { Test } \\
\text { Oracle } \\
\text { per } \\
\text { XACML }\end{array}$} & \multirow{2}{*}{$\begin{array}{c}\text { Actual } \\
\text { Result by } \\
\text { Balana }\end{array}$} \\
\hline & $\begin{array}{c}\text { Decision of } \\
\text { Policy } 1\end{array}$ & $\begin{array}{l}\text { Decision } \\
\text { of Policy } 2\end{array}$ & & \\
\hline 1 & $\mathrm{I}(\mathrm{D})$ & Permit & $\mathrm{I}(\mathrm{DP})$ & $\mathrm{I}(\mathrm{D})$ \\
\hline 2 & $\mathrm{I}(\mathrm{D})$ & $\mathrm{I}(\mathrm{P})$ & I(DP) & $\mathrm{I}(\mathrm{D})$ \\
\hline 3 & Permit & $\mathrm{I}(\mathrm{D})$ & I(DP) & $\mathrm{I}(\mathrm{D})$ \\
\hline 4 & $\mathrm{I}(\mathrm{P})$ & $\mathrm{I}(\mathrm{D})$ & $\mathrm{I}(\mathrm{DP})$ & $\mathrm{I}(\mathrm{D})$ \\
\hline
\end{tabular}

In addition, the initial version of Balana used in our project failed the conformance tests of the Permit-unless-deny policycombining algorithm. Examination of the source code revealed that the bugs resulted from the copy-paste of the Deny-unlesspermit policy-combining algorithm. This has been fixed in the current version of Balana, though.

\section{RELATED WORK}

Existing work on XACML-related testing has focused on the testing of XACML policies, not the implementation of the XACML standard. Thus, no literature is directly comparable to this paper. In Cirg [8], tests are generated from counterexamples produced by the change-impact analysis of two synthesized versions of an XACML policy. The difference of the two versions of a policy targets a test coverage goal (e.g., rule, or condition). Targen [9] is a test generator for XACML policies that derives access requests to satisfy all the possible combinations of truth values of the attribute id-value pairs found in a given policy. Access requests generated by Cirg and Targen typically use a limited number of subject, resource, action, and environment attributes. A real request, however, could use any combination of attributes. Because requests are encoded in XML, they must conform to the XML Context Schema. To address this issue, Bertolino et al., have developed several test generation algorithms [2][3][4][5]. These algorithms can generate requests that use more than one subject, resource, action, or environment attribute. They can also produce robustness tests, where invalid attribute values are generated randomly. Li et al. have applied symbolic execution technique to generation of access requests for testing XACML policies [7]. They convert the policy under test into semantically equivalent C Code Representation (CCR) and symbolically execute CCR to create test inputs and translate the test inputs to access control requests. $\mathrm{Xu}$ et al., have proposed a fault-based testing approach for determining existence or absence of incorrect combining algorithms in XACML 3.0 policies [12].

\section{CONCLUSIONS}

We have presented an approach to the conformation testing of Balana, which is currently the only open source implementation of the XACML3.0 standard. Our experiment has revealed subtle conformance issues. The decision tables used to define the conformance test requirements are not only useful for testing XACML3.0 implementations, but also provide important guidelines for understanding the meanings of XACML3.0 language elements. In particular, the various rule combining algorithms and policy combining algorithms have subtle differences and similarities.

\section{ACKNOWLEDGMENT}

This work was supported in part by US National Science Foundation (NSF) under grants CNS 1359590 and 1461133. Dr. Yunpeng Zhang and Mr. Ning Shen participated in the initial conformance testing of XACML combining algorithms.

\section{REFERENCES}

[1] Balana, "Open source XACML 3.0 implementation," http://xacmlinfo.org/2012/08/16/balana-the-open-source-xacml-3-0implementation/, 2012.

[2] A. Bertolino, S. Daoudagh, F. Lonetti, and E.marchetti. "Automatic XACML requests generation for policy testing." Fifth IEEE International Conference on Software Testing, Verification and Validation (ICST), 2012, pp.842-849.

[3] A. Bertolino, S. Daoudagh, F. Lonetti, and E.marchetti. "The XCREATE Framework-A Comparison of XACML Policy Testing Strategies." Proc. of the 8th International Conference on Web Information Systems and Technologies (WEBIST). pp.155-160.

[4] A. Bertolino, S. Daoudagh, F. Lonetti, and E. Marchetti. "Xacmut: Xacml 2.0 mutants generator." Sixth IEEE Int'l Conf. on Software Testing, Verification \& Validation Workshops (ICSTW). 2013, pp.2833.

[5] A. Bertolino, S. Daoudagh, F. Lonetti, E. Marchetti and L. Schilders. "Automated testing of extensible access control markup language-based access control systems." Software, IET 7.4 (2013), pp.203-212.

[6] V. C. Hu, D. Ferraiolo, R. Kuhn, A. Schnizer, K. Sandlin, R. Miller and K. Scarfone. "Guide to Attribute Based Access Control (ABAC) Definition and Considerations." NIST Special Pub 800 (2014): 162.

[7] Y. C. Li, Y. Li, L. Z. Wang, and G.Chen. "Automatic XACML Requests Generation for Testing Access Control Policies." Proc. of the 26th International Conf. on Software Engineering and Knowledge Engineering (SEKE'14), Vancouver. July 2014.

[8] E. Martin and T. Xie. "Automated test generation for access control policies," in Supplemental Proc. of ISSRE, November 2006.

[9] E. Martin, and T. Xie. "Automated test generation for access control policies via change-impact analysis." Proceedings of the Third International Workshop on Software Engineering for Secure Systems. IEEE Computer Society, 2007, pp.5-11.

[10] E. Martin, and T. Xie. "A fault model and mutation testing of access control policies." Proceedings of the 16th International Conference on World Wide Web. ACM, 2007, pp.667-676.

[11] OASIS, “eXtensible Access Control Markup Language (XACML) Version 3.0," http://www.oasisopen.org/committees/xacml/, 2013.

[12] D. Xu, N. Shen, Y. Zhang, "Fault-based testing of combining algorithms in XACML 3.0 policies," Proc. of the 27th Int'l Conf. on Software Engineering and Knowledge Engineering (SEKE'15), 2015.

[13] D. Xu, Y. Zhang, N. Shen, "Formalizing semantic differences between combining algorithms in XACML 3.0 policies," Proc. of the 2015 International Conference on Software Quality, Reliability and Security (QRS'15), pp. 163-172. Vancouver, Canada. August 2015. 